\title{
Preparedness and Response Efforts to Fight against COVID-19 in Sub-Saharan Africa: Challenges and Opportunities
}

\author{
Moges Workneh Ayele ${ }^{1}$ and Birhanu Demeke Workneh ${ }^{2}$ \\ ${ }^{1}$ Department of Pediatric Nursing, College of Medicine and Health \\ Science, Wollo University, Dessie, Ethiopia \\ ${ }^{2}$ Departments of Pharmacy, College of Medicine and Health Science, \\ Wollo University, Dessie, Ethiopia
}

\author{
${ }^{*}$ Corresponding author \\ Moges Workneh Ayele, Department of Pediatric Nursing, College of Medicine \\ and Health Science, Wollo University, Dessie, Ethiopia
}

Submitted: 03 Apr 2020; Accepted: 09 Apr 2020; Published: 16 May 2020

\begin{abstract}
In late December the World Health Organization declared COVID-19 as global pandemic and needs international concern. As the novel corona virus rages through the world and spreads rapidly Africa is the least-affected continent at the moment. Sub-Saharan Africa is the home of more than one billion populations with fragile health system which is prone for the epidemic to occur. But Ebola experience left many African countries better prepared. We were searching all sources of the website related to preparation and prevention of COVID-19 in sub-Sahara Africa countries. Most African countries have established laboratory facility and implement the recommendations that terminate the outbreak COVID-19.
\end{abstract}

Keywords: COVID-19, Sub-Sahara Africa, Health Care

\section{Introduction}

The outbreak COVID-19 in our planet has been unprecedented in its scale and impact. The emergence and spread of a novel corona virus (2019-nCoV) from Wuhan, China, has become a global health concern [1]. Shortly after the detection of the corona virus in late December 2019, several countries have reported sporadic imported cases among travelers returning from China which should that human to human transmission was occurred [2]. Repeated outbreak of well-known existing, emerging and reemerging disease, and potentially appeared to be epidemic impose their toll on the health system of many sub-Saharan Africa countries [3]. When the World Health Organization (WHO) declared the disease, officially COVID-19 as a Public Health Emergency of International Concern (PHEIC) on 31st January 2020, the Director General Dr Tedros Ghebreyesus justified the decision by stating that WHOs the greatest concern is the potential for the virus to spread to countries with weaker health systems [4].

Sub-Saharan Africa is the home of more than one billion population with fragile health system which is prone for the epidemic to occur. The outbreak of different infectious diseases epidemic in the region left important lesson regard to the identification of cases and break transmission. The outbreak of Ebolavirus in West Africa between 2014-2016 providing a lesson for the affected country how to rapidly identify the infection and halt transmission [5]. Democratic republic of Congo also demonstrated the important lesson from its tenth outbreak of Ebola virus disease (Ebola) in between 20-18-2019, even for health services with considerable experience of dealing with a certain emerging pathogen, geography, and sociopolitical instability, can hamper the response [6]. The majority of sub-Sahara Africa countries are experienced an epidemic. Rift Valley fever outbreak regularly occur in subSaharan Africa, Zika virus outbreak in Uganda Chikungunya virus epidemic was recorded in DRC, Central African Republic, Malawi, Uganda, Burundi, Angola, Guinea, South Africa and Nigeria [7, 8]. The aim of the paper is assessed the level of preparedness and efforts of sub-Sahara Africa to fight against the outbreak of COVID-19. The WHO's joint external evaluation reports, conducted since 2016, suggest that the ability to respond an international health regulation hazard, such as the importation of an infectious disease like COVID-19, requires almost universal improvement across sub-Saharan Africa [9]. Thus, it is crucial for sub-Saharan African countries become proactive and prepare surveillance systems for the rapid detection of any imported and local transmission cases of COVID-19, to prevent rapid spread as seen in Italy. There has been rapid response to the COVID-19 epidemic from Africa's public health systems, well before any cases of COVID-19 had been reported from Africa. This response has been made possible with the implementation of programs in collaboration with WHO is including the creation of the World Health Emergencies program, the establishment of the Africa Centers for Disease Control and Prevention (Africa CDC, 2020) and creation and funding of consortia such as the ONE-HUMANANIMAL-HEALTH Africa- Europe research, training, and capacity development network (PANDORA-ID-NET)(PandoraID-NET, 2020) for tackling emerging and re-emerging infections with epidemic potential [10].

\section{Methods}

Search strategies were developed using a combination a word coronavirus and the name of each country. The website of the minister of health of each country was also searched for preparation of the country to control the coronavirus spreading including the test in the entry point of airport, the preparation of facility for quarantine, 
human power, mobilization of a resource and awareness creation in the community and lows which support the termination of the virus transmission.

\section{Result and Discussion}

Currently, 33 of 47 sub-Saharan African countries have testing facilities, up from only two in January (in South Africa and Senegal). Among the sub-Sahara African countries Algeria, South Africa, Nigeria, and Ethiopia have the highest importation risk while Sudan, Angola, Tanzania, Ghana, and Kenya were identified as having a moderate importations risk [11]. A country's response capacity depends on the strength of its emergency preparedness and the regular testing and updating of national plans and capacities [12]. Soon after the spread of corona virus from china to other country in the world bout six laboratories in sub-Sahara Africa were established including the Institute Pasteur in Senegal, and the National Institute for Communicable Diseases in South Africa, were able to test to the virus, raising concern that undetected cases might already exist. Africa CDC ran a workshop in Senegal for scientists in 15 countries, sending them home with diagnostic tests including reagents. WHO has conducted a survey with countries to assess their overall readiness for COVID-19 and found the regional readiness level was an estimated $66 \%$ [13].

Africa is now better prepared than ever before. Amref Health Africa, Africa CDC with WHO are working with sub-Saharan African minister of health to strengthen in all aspects of prevention and control of COVID-19. Countries already set emergency toll free numbers. A day after Ethiopian Prime Minister Abiy Ahmed announced a corona virus support package for the whole of Africa, Chinese business mogul Jack Ma, donated corona virus kit and reagent [14]. Sub-Saharan Africa as the part of Africa region Africa's preparedness efforts have been boosted with \$25 million from the Bill \& Melinda Gates Foundation, with some of it going towards training. When an outbreak is caused by an airborne pathogen and physical contact, population density or crowding is known to directly affect the spread of infection [11].

As a result, all regions of the countries have been promoted the recommendations washing of hands with soap and water for at least 20 seconds, or cleaning hands with alcohol-based solutions; and social distance of stay 1 meter or more away from people infected with COVID-19 who are showing symptoms. Air and sea travel have suspended with Europe and chain. All countries have implemented border screening including commenced temperature screening, symptom screening, and/or questionnaires for arriving passengers from China. Nigeria is sub-Saharan Africa's first country to register a case of the virus and the country provides aggressive and intensive health education on respiratory hygiene in the media, schools, hospitals, churches, and mosques to prevent the spread of COVID-19. Republic of the Congo a lot of the infrastructure needed to diagnose, isolate and treat severe cases is already in place due to Ebola. Reactions of towards the epidemic COVID-19 includes on the office of the Ethiopian prime minister announced that schools, sporting events, and public gatherings shall be suspended for 15 days and the Ethiopian airlines suspended flights to 30 countries affected with the corona virus with anyone entering the country should undergo a mandatory self-quarantine for 14 days, Night clubs in Addis Ababa are also to remain closed until further notice, all land borders and deployed security forces to halt the movement of people along the borders and finally, Universities are closed, and students wet to home [15, 16]. Kenya, South Africa, Uganda and Tanzania have banned all major public events including sporting events, open-air religious meetings, closing its borders to people flying in from hard-hit countries, and all events of a huge public nature' have been suspended [17]. In Kenya, the government has opened a quarantine center in the capital, Nairobi, for suspected cases similarly, in Tanzania, the health minister announced that isolation centers in the north, east, and west of the country had been identified. Thermometers have been stockpiled and more than 2,000 health workers trained.

The East African nation which hosts many international conferences, has also banned, such meetings for the next month while Uganda has introduced a mandatory 14-day period of self-quarantine for travelers arriving from 16 countries to prevent the spread of the corona virus. Ethiopia is bolstering preparedness to contain a potential outbreak of including strengthening up surveillance, diagnosis, epidemic response coordination and public health education, Universities are closed and send students to their family. An isolation center is being set up and more equipment and supplies needed to prevent and control a potential outbreak were also being procured with the help of WHO. Sub-Saharan Africa has been made impressively in both coverage and equity over the last couple of decades under the umbrella of one health collaborative activities [18]. A number of scholarships have been offered for health-care personnel in an attempt to meet the human resource challenges such scholarships provided a significant contribution to the preparation of the public health workforce in Africa [19]. There are also partners significantly involved in mobilizing a response to the last four Ebola outbreaks in sub-Saharan Africa and build long-term local capacity within health care systems to ensure that they are prepared for future public health emergencies. Sub-Saharan Africa public health professional should be working tirelessly in diseases surveillance and bring collaborative efforts both from the government and none governmental organization to avert COVID-19 infection.

\section{Conclusion}

Sub-Saharan Africa will defend COVID-19 that employing the lesson experienced from Ebola and with the proactive measure that have been implemented since the outbreak of COVID-19.

\section{Competing Interests}

The authors declare that they have no competing interests.

\section{References}

1. Li Q, Guan X, Wu P, Wang, X, Zhou L, Tong Y, et al. (2020) Early transmission dynamics in Wuhan, China, of novel coronavirus-infected pneumonia. N Engl J Med 2020 382: 1199-1207.

2. Pass HI, Ball D, Scagliotti GV (2018) IASLC Thoracic Oncology. 2nd ed. Philadelphia: Elsevier, 2018: 23-29.e3

3. Boutayeb A, Preedy V, Watson R (2010) The impact of infectious diseases on the development of Africa. Handbook of disease burdens and quality of life measures. New York: Springer Science+ Business Media, LLC 2010: 1171-1188.

4. WHO (2019) Coronavirus disease (COVID-19) outbreak. 2020. 
5. Bell BP, Inger $\mathrm{K}$ Damon, Daniel B Jernigan, Thomas A Kenyon, Stuart T Nichol, et al. (2016) Overview, control strategies, and lessons learned in the CDC response to the 2014-2016 Ebola epidemic. MMWR supplements 65: 4-11.

6. Aruna A, Mbala P, Minikulu L, Mukadi D, Bulemfu D, et al. (2019) Ebola Virus Disease Outbreak-Democratic Republic of the Congo, August 2018-November 2019. Morbidity and Mortality Weekly Report 68: 1162-1165.

7. Gubler D J, Vasilakis N, Musso D (2017) History and emergence of Zika virus. J Infect Dis 216: S860-S867.

8. Wahid B, Ali A, Rafique S, Idrees M (2017) Global expansion of chikungunya virus: mapping the 64-year history. Int J Infect Dis 58: 69-76.

9. WHO African Region (2020) JEE mission reports.

10. Africa centers for disease control and prevention. [Accessed 23 march 2020].

11. Nkengasong JN, Mankoula W (2020) Looming threat of COVID-19 infection in Africa: act collectively, and fast. The Lancet 395: 841-842.

12. Kandel N, Chungong S, Omaar A, Xing J (2020) Health security capacities in the context of COVID-19 outbreak: an analysis of International Health Regulations annual report data from 182 countries. The Lancet 395: 1047-1053.
13. Acharya KP (2020) Resource poor countries ought to focus on early detection and containment of novel corona virus at the point of entry. Clinical Epidemiology and Global Health.

14. How Ebola is helping the Democratic Republic of the Congo prepare for coronavirus disease.

15. Ethiopia starts deployment of Jack Ma's coronavirus donation

16. COVID-19: Ethiopia closes schools, bans public events". aa.com.tr. Retrieved 23 March 2020.

17. Ethiopia Suspends Flights To 30 Countries"fanabc.com. Retrieved 23 March 2020.

18. Duncan Miriri, Omar Mohammed (2020) Kenya bans public events after first case of coronavirus.

19. Mokwena K, Mokgatle-Nthabu M, Madiba S, Lewis H, NtuliNgcobo B, et al. (2007) Training of public health workforce at the National School of Public Health: meeting Africa's needs. Bulletin of the world Health Organization 85: 949-954.
Copyright: (02020 Moges Workneh Ayele. This is an open-access article distributed under the terms of the Creative Commons Attribution License, which permits unrestricted use, distribution, and reproduction in any medium, provided the original author and source are credited. 